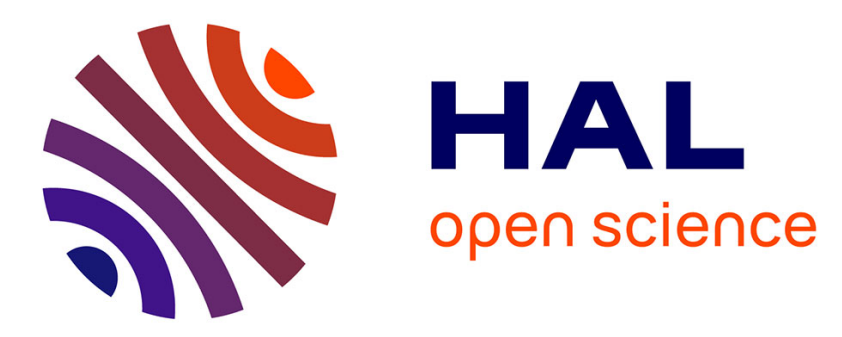

\title{
Knowledge, attitudes, and practices related to epilepsy in rural Burkina Faso
}

Athanase Millogo, A. Helena Ngowi, Hélène Carabin, Rasmané Ganaba, Alida Da, Pierre-Marie Preux

\section{To cite this version:}

Athanase Millogo, A. Helena Ngowi, Hélène Carabin, Rasmané Ganaba, Alida Da, et al.. Knowledge, attitudes, and practices related to epilepsy in rural Burkina Faso. Epilepsy \& Behavior, 2019, 95, pp.70-74. 10.1016/j.yebeh.2019.03.006 . hal-02275329

\section{HAL Id: hal-02275329 \\ https://hal-unilim.archives-ouvertes.fr/hal-02275329}

Submitted on 22 Oct 2021

HAL is a multi-disciplinary open access archive for the deposit and dissemination of scientific research documents, whether they are published or not. The documents may come from teaching and research institutions in France or abroad, or from public or private research centers.
L'archive ouverte pluridisciplinaire HAL, est destinée au dépôt et à la diffusion de documents scientifiques de niveau recherche, publiés ou non, émanant des établissements d'enseignement et de recherche français ou étrangers, des laboratoires publics ou privés.

\section{(ㄷ)(1) $\$$}

Distributed under a Creative Commons Attribution - NonCommercial| 4.0 International 


\section{Knowledge, attitudes and practices related to epilepsy in rural Burkina Faso}

Athanase Millogo ${ }^{1,5 *}$ A. Helena Ngowi ${ }^{2}$, Hélène Carabin ${ }^{3}$, Rasmané Ganaba ${ }^{4}$, Alida $\mathrm{Da}^{4}$, Pierre-Marie Preux ${ }^{5}$

${ }^{1}$ Department of Internal Medicine, Sourô Sanou University Teaching Hospital, Bobo-Dioulasso, Burkina Faso

${ }^{2}$ Department of Veterinary Medicine and Public Health, Sokoine University of Agriculture, Morogoro, Tanzania

${ }^{3}$ Department of Biostatistics and Epidemiology, College of Public Health, University of Oklahoma Health Sciences Center, USA

${ }^{4}$ Agence de Formation, de Recherche et d'Expertise en Santé pour l'Afrique (AFRICSanté), BoboDioulasso, Burkina Faso

5INSERM, University of Limoges, CHU Limoges, UMR_S 1094, Tropical Neuroepidemiology, Institute of Neuroepidemiology and Tropical Neurology, F-87000 Limoges, France

*Corresponding author: Souro Sanou University Teaching Hospital, 01 BP 676 Bobo-Dioulasso, Burkina Faso. Fax: +226 20972693.

E-mail address: athanase.millogo@gmail.com. 


\section{Abstract}

Objectives: To assess knowledge, beliefs, attitudes and practices regarding epilepsy and neurocysticercosis in rural areas in Burkina Faso. Materials: The interviews were designed to assess general perception of epilepsy, cultural beliefs and practices regarding epilepsy and people with epilepsy (PWE), and knowledge about the link between human epilepsy and porcine cysticercosis. This qualitative study used in-depth interviews with different categories of community members, including PWE, healthcare providers (HCPs) and traditional healers in three villages in rural Burkina Faso. Results: All respondents showed a good knowledge of epilepsy symptoms but very little knowledge on causes of the disease. In this community, epilepsy was often associated with witchcraft (commonly termed "black magic"). People with epilepsy were marginalized and denied certain rights such as school education and marriage. They also relied mainly on traditional medicine with a prominent role played by traditional healers. While medical personnel knew that controlling seizures would depend on the cause, the traditional healers reported to be able to cure all kinds of epilepsy as long as the patient adhered to taboos. The main "treatments" prescribed by traditional healers were to stay away from fire and refrain from pork consumption. Pork fat was believed to reduce the effectiveness of the traditional medicine. Conclusion: For effective monitoring and management of epilepsy in Burkina Faso, there is a need to promote better knowledge of the disease in the community, including HCPs, and traditional healers.

Key-words: Attitudes; Beliefs; Burkina Faso; Epilepsy; Knowledge; Qualitative research. 


\section{Background}

Epilepsy is a chronic non-communicable disorder of the brain that affects people of all ages. More than $80 \%$ of epilepsy cases worldwide live in developing countries $[1,2]$. The perception of the condition varies according to regions and cultures. In many developing countries, the fear of discrimination and stigma makes people with epilepsy (PWE) hide their condition or feel that it brings shame to themselves or their relatives [3-6]. This fear may also lead to PWE seeking treatment from traditional healers instead of seeking care from modern health services [7]. Many studies worldwide have shown that PWE are forbidden to marry or attend schools [8-13]. In many Sub-Saharan African countries, traditional beliefs lead most PWE to opt for traditional treatment, resulting in inadequate management of the disease $[11,14-19]$. As the majority of PWE do not seek health care services, the magnitude of epilepsy cannot be accurately estimated through medical data. The insufficiency of expertise in neurology also leads physicians at the primary care and hospital levels to neglect epilepsy [20]. In Burkina Faso only seven neurologists, who practice in the two major urban areas of the country, serve the population of 13.6 million people. This obvious resource-gap leads to an important under-estimation of the burden of epilepsy in the country.

Epilepsy can be caused by various factors, including congenital, infectious and physical factors (such as head injuries). Neurocysticercosis (NCC) has recently emerged as an important infectious cause of epileptic seizures in areas where Taenia solium is endemic. A meta-analysis reported the frequency of NCC in PWE to be consistent across endemic countries, accounting for approximately $29.0 \%(95 \% \mathrm{Cl}: 22.9 \%-35.5 \%)$ of PWE [21]. Knowledge on this infectious cause of epilepsy would enable implementation of appropriate interventions for this treatable and preventable cause of epilepsy. 
Studies conducted around the world suggest that perceptions and attitudes towards epilepsy vary according to different cultural settings [8, 11, 13, 15-17, 19, 21, 22]. In Burkina Faso, each of the 60 ethnic groups has specific beliefs towards epilepsy and uses a different name for the disease. The few studies ever conducted on knowledge, attitudes and perceptions towards epilepsy were done in urban areas in the western part of the country [23-26], and no study had assessed these aspects of epilepsy in rural areas. A better understanding of knowledge, attitudes and perceptions of epilepsy would guide the development of appropriate educational programmes on epilepsy in addition to guiding the healthcare providers to better manage the disease. Understanding knowledge, perceptions, attitudes and behaviours of various care givers regarding epilepsy provides a unique feature of this study as most previous studies gathered such information primarily from PWE and the general population. The main objective of this study was to assess knowledge, beliefs, attitudes and practices of PWE, community members, traditional healers and health care providers (HCPs) regarding epilepsy and NCC in rural areas in Burkina Faso.

\section{Methods}

\section{Study sites}

This qualitative exploratory study was part of a pilot study conducted in 2007 to assess the presence of cysticercosis and its association with epilepsy in three villages of Burkina Faso (Figure 1). Details about the main study can be found elsewhere [27-30].

\section{Study population and sampling procedure}

The inclusion criteria for study participants were: being over the age of 16 and agreeing to participate in the interviews, irrespective of gender or religion. In each study village, participants were classified into five categories based on their age, professions and epilepsy statuses. The following participant groups were used: young adults ( $\geq 16-40$ years), older 
adults ( $\geq 40$ years), traditional healers, health care providers (HCPs), and PWE. There was no traditional healer in Nyonyogo. Inclusion of these different groups aimed at obtaining information from people with different roles in the community. To obtain the required categories of respondents, purposive sampling was adopted as it was the most appropriate approach. Local leaders guided the research team in this procedure after the leaders were informed about the objectives of the study.

\section{Study design and data collection procedure}

This was a qualitative exploratory study. A semi-structured interview guide created by the first author (Athanase Millogo) was used to conduct one-on-one in-depth interviews with each study participant. The interview guide consisted of five major topics which were used to initiate the discussions and probing was used to explore the issues further. The interviews were designed to assess general perception of epilepsy, cultural beliefs and practices towards epilepsy and PWE, and knowledge about the link between human epilepsy and porcine cysticercosis. All interviews were conducted by one of the co-authors (Alida Da). The guide was pilot tested in a different village before its use. All interviews were recorded using a voice recorder. The interviews were tape-recorded in local languages (Moore or Lyele) depending on the setting and lasted from 20 to 40 minutes.

\section{Data analysis}

The tape-recorded interview scripts were transcribed in Microsoft Word and translated from the local languages into French and English and back translated in Moore or Lyele to insure the accuracy of the translations. The translations were made by interpreter using Moore or Lyele as native language and able to translate from French to Moore or Lyele. Data were analyzed by three independent analysts (Alida Da, Athanase Millogo, Helena A. Ngowi) using N-VIVO version 1.1, note based analysis and MAXQDA, respectively. The reason for having 
three independent analysts was for triangulation to verify the conclusions reached. Data were coded by assigning same codes in passages or quotations with similar concepts. The codes were then quantified to identify thematic ideas for each aspect investigated. A theme was identified if an idea was mentioned by at least $60 \%$ of respondents. The first stage of analysis involved all respondents regardless of the village to identify the main emerging and recurring themes related to the research questions [31]. The themes were not predetermined. Rather they emerged from the data under each topic of discussion based on content analysis. Agreement between the different analysts was over $87 \%$ in all topics investigated. Having analyzed the responses generally across the groups, the analysts compared the responses to similar questions between the different categories of respondents (normal villagers, PWE, HCPs and traditional healers) by analyzing each case independently.

\section{Ethics}

The study protocol was reviewed and approved by the ethical committee of the Centre MURAZ (Ref. 02-2006/CE-CM) and by the Institutional Review Board of the University of Oklahoma Health Sciences Center (IRB\# 12694). Each participant was asked to read or, if not able to read, was read an informed consent. The interviewer (A. D.) answered any question that that the potential participant may have about the study. Individuals willing to participate signed the consent form or oral consent was obtained and documented by A. D. on the consent form for those who could not read. Participants' unique identifications were kept confidential and each participant had the right to stop the interview at any time.

\section{Results}


Twenty-nine people were asked and agreed to participate in the study ( 21 males, 8 females), including young adults $(n=10)$, older adults $(n=9), \operatorname{PWE}(n=6), \operatorname{HCPS}(n=2$ who were present at the time of the study) and traditional healers $(n=2)$. Ten of the respondents were residing in Batondo, 10 in Pabré and nine in Nyonyongo. Most respondents $(n=23)$ had no formal education, six had elementary or primary school education and one HCP had a high school education. A total of 7 main themes emerged and were related to the perception of disease and health, perceived causes of epilepsy, clinical symptoms of epilepsy, social behavior towards PWE, link between epilepsy and pork consumption, risk for person to become epileptic, knowledge about treatment and therapeutic itineraries. The mean age of respondents was 41.2 years.

\section{Knowledge about epilepsy and its perceived causes}

Recognition of epilepsy and names referring to the condition

All respondents had a good knowledge of epilepsy symptoms. "During the seizure, the subject shouts, stays motionless for a while, dribbles, loses consciousness" and "he (PWE) may fall down and lose urine involuntarily". This description is related to tonic-clonic seizures which are generally well recognized in the community. Epilepsy was referred to as "councounbolo" (i.e disease that starts suddenly) or "kimina mayolo" (i.e bad disease) in Batondo. In Pabré and Nyonyogo, epilepsy was locally called "bamsobdoum" (i.e disease that makes you faint) or "kissinkiri" (i.e epilepsy).

Knowledge of the causes of epilepsy

There was little knowledge about the causes of epilepsy among all groups except the HCPs. The theme idea that emerged during the interviews was that epilepsy was caused by witchcraft (spells) or satanic (evil spirits) causes. A HCP from Batondo stated "Most of the 
time, this disease (epilepsy) is associated with evil spirits. That is why the persons with epilepsy begin treatment with traditional methods". A PWE from Nyonyogo said: "I got this disease from evil spirits". Another PWE from Pabré said: "It is a disease some spirits passed on me. One day, as I was riding my bicycle, I felt an invisible force dragging the bicycle, and eventually I fell off". Congenital causes have also been mentioned by a young man from Batondo: "A person can be born with it". Other causes were also mentioned such as contact with saliva or the left hand of PWE during seizures. A few individuals mentioned other causes such as pork consumption. In this case, epilepsy was mainly associated with pork fat. In summary, the participants identified two broad categories for the causes of epilepsy namely mystical, which was by far the most common, and genetic causes. No respondent mentioned a link between undercooked pork consumption, poor sanitation and epilepsy.

\section{Attitudes and perceptions of PWE regarding epilepsy}

The theme idea that resulted from this topic was that PWE choose traditional rather than modern medicine for treatment. In addition, all PWE interviewed were willing to receive some type of treatment. However, the interviews with PWE suggested that they would resort to modern medicine only if complications such as burns or other injuries associated with seizures were to occur or if traditional medicine fails. Priority to traditional over modern medicine was due to a local perception that epilepsy was specifically an African disease, and hence a belief that "White people" which meant modern medicine, had no medicine to cure it. A traditional healer from Pabré said: "Most of the time, the disease is linked to evil spirits... When they go to the dispensary, they don't recover because it is an African disease". Other unique causes were mentioned, such as a respondent from the older adults stating "It is a disease passed on to human beings by cats through food. When a cat's 
mouth gets in contact with food or when the animal licks a container later used unwashed, it leaves epilepsy germs."

Responses indicated a frequent switch to modern medicine with satisfactory results. Here is the point of view of one PWE from Batondo: "First I began with traditional treatments. My family did not want me to follow modern treatment. They thought that modern medicine cannot cure it... It is only last year that I began to go to the dispensary". One important prescription for patients under traditional medicine was to refrain from pork consumption. The fat in the pork was said to inhibit the action of traditional medicines. Some PWE asserted having consulted traditional healers, this move being the first contact taken in their health seeking behaviour. According to traditional healers, epilepsy could be cured if one followed the treatment regimens and prescriptions whereas the HCPs believed that contrary to epilepsy from other causes, the inherited form was difficult to cure.

Respondents seemed sceptical about the effectiveness of modern treatment of epilepsy since they mentioned monitoring its effect on the seizures very closely. Even the medical nurse in Nyonyogo did not seem to be quite confident in the effectiveness of modern treatment for epilepsy: "There are treatments but you rarely see anybody who has been cured." This point is of great interest as HCPs are supposed to provide appropriate information to their community.

One PWE in Pabré village said: "I had a traditional treatment when my children decided to take me to a doctor. I am currently undergoing a treatment by a doctor. It is nearly 10 months I have not had any seizure."

\section{Individual and social attitude towards epilepsy}


Epilepsy affects the social role and the productivity of PWE. It creates an emotional and socio-economic burden to the caretakers of the patient. This burden leads to marginalization of PWE and their families. When respondents were asked on their attitudes towards PWE, there were various ideas, but no specific theme was identified. However, all the ideas revolved around moral suffering and stigma affecting PWE. Having epilepsy was perceived to be a shame to the family, and hence, most PWE in the study community were rejected. A traditional healer from Pabré said: "As epilepsy is a shameful disease, the epileptic individual is marginalized. He cannot enjoy the same rights as healthy people".

When the respondents were asked how other people in their village behaved towards PWE, two themes emerged: marginalization and denial of some rights such as school education, jobs, social interaction, and certain foods. A young lady with epilepsy confessed "... I am not badly ill-treated but I feel that they have no respect for me... I am excluded from what happens in the family. I have even been forbidden from managing my income on the ground that I am unable to do it".

PWE face various types of social problems as they are often denied the right to decide for themselves, because, as reported one respondent from the older adults: "They are not in full possession of their mental faculties". This can be illustrated by the words used by a woman with epilepsy from Batondo: "People do not actually like the person affected by epilepsy. They do not like to interact with him or her... No consideration for me at all. When I try to take interest in something, they find that I am different from other people and should therefore refrain from interfering..." Another PWE from Batondo said "I am not respected. I do not have the right to go to public places. I have been given a separate cup and plate. They do not want me to get married..." 


\section{Knowledge about the link between pork consumption and epilepsy}

When respondents were asked whether there was any link between epilepsy and pork consumption, the theme was a lack of knowledge of the link, even indirect. A few respondents (including a $\mathrm{HCP}$ ) mentioned that cysts in pork meat could be associated with epilepsy. Most other respondents associated human epilepsy with consumption of pork fat. Nevertheless, there was an indication that part of the knowledge on the link between epilepsy and pork consumption was influenced by the interviewer. For example, one respondent from Batondo said: "If what you said about the link between epilepsy and pork is true, therefore all villagers here are at risk since it is only this meat that we eat here". Possible link between pork and epilepsy was also mentioned by a young respondent from Pabré village: "They (butchers) said that white cysts in pork can transmit epilepsy when the meat is not properly cooked." The following assertion is from a PWE in Pabré: "... My doctor told me that there is a relationship between epilepsy and insufficiently cooked pork...". This awareness is interesting to note as it could be a starting point for sensitization to good practice in cooking meat and also good sanitation in this community.

\section{Discussion}

This is the first qualitative study about the perception and attitudes toward epilepsy conducted a rural setting in Burkina Faso. We found that the knowledge about the causes of epilepsy was generally poor, that the indirect link between pork consumption and epilepsy was generally unknown, and that beliefs and attitudes towards PWE lead to stigmatization. In many African countries, community members generally demonstrate good knowledge about the symptoms of epilepsy, especially those associated with generalized tonic-clonic seizures as reported in many other countries in Africa $[14,15,16,19,22,23]$. The finding 
that satanic and witchcraft powers as themes for the causes of epilepsy are not unique to this study. Epilepsy has been associated with witchcraft or evils spirits in several other African countries in both urban and rural areas $[4,11,14,16,18,19]$, and in urban areas of Burkina Faso $(25,26)$. Although this was not identified as a theme, some participants did mention transmission from person-to-person through saliva or physical contact as a possible cause of epilepsy, like others have found in several other countries $[13,14,19,32]$.

One nurse was unsure of the effectiveness of modern treatment for epilepsy. The nurses' response is an important cultural issue. This may be related with this nurse's own cultural perception of epilepsy. The position of this nurse as a HCP and as a credible source of health information for community members is important to consider. HCPs in rural areas may have their own beliefs which could affect their practice, and in this case, discourage PWE from seeking modern treatment. This one statement calls for a larger scale study assessing knowledge of HCPs regarding epilepsy and its treatment in rural Burkina Faso. If the skepticism towards modern medicine is confirmed in this group, a revision of the training curricula for HCPs in Burkina Faso, taking into account cultural values, would be warranted.

Consistent with the beliefs regarding the causes of epilepsy being largely mystical, choosing a traditional treatment over a modern one was identified as a theme among the PWE interviewed. This is in agreement with many studies reporting that traditional medicine is believed to being able to cure epilepsy $[14,15,19,25,26]$. This may also be associated with the belief that the disease only affects African people and hence can only be treated by African medicine. Therefore, the choice of the type of treatment by the patient or his/her family is prompted by their beliefs and opinions about epilepsy in their cultural environment. In many Sub-Sahara African countries, first-line treatment for epilepsy is provided by traditional healers $[24,33,34]$. However, fees for treatment of traditional healers might not 
be cheap [26, 35]. In Burkina Faso, generic forms of phenobarbital are available for less than 1US\$ for a month's treatment, which should be affordable even for the rural and poor communities. Nevertheless, in this study as in many other studies in Sub-Saharan Africa [13, $15-17,19]$, it was observed that modern treatment was not the first choice for PWE. As the first contact of PWE in many areas in Africa, and also because they are more available than the modern HCPs, traditional healers should be included in any screening study and educational programmes about epilepsy in these settings. Because of the role they play in providing care in their community, traditional healers are often know who suffers from epilepsy in their community. They could contribute to building a bridge between traditional and modern medicines in order to reduce the treatment gap of epilepsy in Africa.

In some studies, misconceptions about epilepsy lead to stigma $[9,10,13]$ and stigma discourage PWE to seek modern healthcare. In our study, we found that the stigma resulting from epilepsy largely impacts the patients' social role and productivity. This has been reported in Zambia where women with epilepsy were more likely to deliver their babies at home rather than in a hospital (36). The two themes identified regarding the general attitudes of villagers towards PWE, namely marginalization and denial of some rights, are in agreement with studies that have reported. PWE are forbidden from gardening, attending meetings, sharing meals with other members of their community and attending to public places $[12,15,35]$. Studies conducted in Zambia have demonstrated that even when PWE are self-reliant, their daily life does not always improve [5]. In other studies, PWE have been shown to deny their epilepsy status to avoid stigmatization [12, 35, 36]. It has also been shown that children with epilepsy in urban areas of Burkina Faso are excluded from schools [25] and PWE in Zambia cannot marry or be employed [36], a fact which was reported in our study. Cultural differences in stigma associated with epilepsy may determine whether an 
individual seeks care for epilepsy. To better assess the perceptions and attitudes regarding epilepsy in these rural areas in Burkina Faso, quantitative studies to identify associated factors of the reported attitudes and practices in the community are needed.

Prior to any intervention to improve the management of epilepsy cases, there is a critical need to get the community commitment, help PWE and the surrounding communities to have a better knowledge of the disease and improve their health seeking behaviour. Community programs to achieve these aims should be based on the local perceptions of epilepsy and needs and one must also consider social and cultural conditions in the region 37].

\section{Conclusion}

In order to promote community educational program regarding epilepsy in Burkina Faso, there is a need to take different socio-cultural aspects into consideration, develop collaboration with traditional healers with an informative role. Such a program should address stigma and discrimination towards PWE as well as appropriate management of epilepsy.

\section{Acknowledgments}

We would like to express our gratitude to Chantal Millogo for collecting the data and Léopold Bado for the translation and back translation from French to Lyele. Special thanks to Dr L. Raphaël Nébié and Elie Sawadogo and to all the members of the three villages for their warm welcome and their active participation to the study.

This study was funded by the National Institute for Neurological Disorders and Stroke (NINDS) and the Fogarty International Center (FIC) of the US National Institutes of Health 
(Epidemiology and Burden of Neurocysticercosis in Burkina Faso) (R21 NS055353) as part of the Brain Disorders in the Developing World: Research Across the Life Span (BRAIN) grant program. The funders had no role in study design, collection data and analysis, decision to publish, or preparation of the manuscript.

Conflict of interest statement: The authors have no conflict of interest to declare.

\section{Conflict of interest}

None of the authors has any conflict of interest to disclose 


\section{References}

1. Boer HM, Mula M, Sander JW. The global burden and stigma of epilepsy. Epilepsy Behav; $2008 ; 12: 540-546$.

2. Ba-Diop A, Marin B, Druet-Cabanac M, Ngoungou EB, Newton CR, Preux PM. Epidemiology, causes, and treatment of epilepsy in sub-Saharan Africa. Lancet Neurol. 2014; 13: 1029-1044.

3. Atadzanov M, Haworth A, Chomba EN, et al. Epilepsy-associated stigma in Zambia: what factors predict greater felt stigma in a high stigmatized population? Epilepsy Behav 2010, 19: 414-418.

4. Baskind R, Birbeck GL. Epilepsy-associated stigma in sub-Saharan Africa: the social landscape of a disease. Epilepsy Behav 2005, 7: 68-73.

5. Birbeck GL, Kalichi EM. The status of people with epilepsy in rural sub-Saharan Africa. J Neurol Sci, 2003, 209: 65-68.

6. Rafael F, Houinato D, Nubukpo P, et al. Sociocultural and psychological features of perceived stigma reported by people with epilepsy in Benin. Epilepsia 2010, 51: 1061-1068.

7. Kumari P, Ram D, Haque Nizamie S, Goyal N. Stigma and quality of life in individuals with epilepsy: A preliminary report. Epilepsy Behav 2009, 15: 358-361.

8. Cuong LQ, Thien DD, Jallon P. Survey of public awareness, attitudes, and understanding towards epilepsy in Nhan Chinh, Hanoi, Vietnam. Epilepsy Behav 2006; 8: 176-80.

9. Barennes H, Tran DS, Latthaphasavang V, et al. Epilepsy in Lao PDR: From research to treatment intervention. Neurology Asia 2008; 13: 27-31.

10. Hasan SS, Alen YKS, Wayne WGW, et al. Understanding of and attitudes toward epilepsy among the urban Chinese population in Malaysia. Singapore Med J 2010; 51: 290-299. 
11. Ndoye NF, Sow AD, Diop AG, et al. Prevalence of epilepsy, its treatment gap and knowledge, attitudes and practice of its population in sub-urban Senegal: an ILAE/IBE/WHO study. Seizure 2005; 14: 106-111.

12. Nuhu FT, Fawole JO, Babalola OJ, Sulaiman ZT. Social consequences of epilepsy: a study of 231 Nigerian patients. Ann Afr Med 2010; 9: 170-175.

13. Tran DS, Odermatt $P$, Singphuoangphet $S$, et al. Epilepsy in Laos: knowledge, attitudes, and practices in the community. Epilepsy Behav 2007; 10: 565-570.

14. Matuja WB, Rwiza HT. Knowledge Attitude and Practice towards epilepsy in secondary school students in Tanzania. Central Afr J Med 1994; 40: 13-18.

15. NJAMNSHI AK, TABAH EN, YEPNJIO FN, et al. General public awareness, perceptions, and attitudes with respect to epilepsy in the Akwaya Health District, South-West Region, Cameroon. Epilepsy Behav 2009, 15: 179-185.

16. Njamnshi AK, Yepnjio FN, Zoung-Kanyi Bissek AC, et al. A survey of public knowledge, attitudes, and practices with respect to epilepsy in Badissa Village, Centre Region of Cameroon. Epilepsy Behav 2009, 16: 254-259.

17. Njamnshi AK, Yepnjio FN, Tabah EN, et al. Public awareness, perceptions, and attitudes with respect to epilepsy in Ebolowa and Sangmelima - Urban Cameroon. Epilepsy Behav 2009, 14: 628-633.

18. Njamnshi AK, Zoung-Kanyi Bissek AC, Yepnjio FN, et al. A community survey of knowledge, perceptions, and practice with respect to epilepsy among traditional healers in the Batibo Health District, Cameroon. Epilepsy Behav 2010, 17: 95-102.

19. Nyame PK, Biritwun RB. Epilepsy: knowledge, attitude and practice in literate urban population, Accra, Ghana. West Afr J Med 1997; $16: 139-135$. 
20. Ministère de la santé (Burkina Faso). Annuaire statistique 2007, 247 pages.

21. Ndimubanzi P C, Carabin H, Budke C. M, et al. A systematic review of the frequency of neurocysticercosis with a focus on people with epilepsy. PLoS Neglected Tropical Diseases 2010; 4(11) e870. doi:10.1371/journal.pntd.0000870.

22. Andriantseheno M, Rakotoarivony MC. Aspects socioculturels de l'épilepsie chez le Malgache. Bull Soc Pathol Exot 2000, 93 :247-250.

23. Millogo A, Kaboré J, Traoré ED, et al. Aspects socioculturels de l'épilepsie en milieu scolaire à Bobo-Dioulasso (Burkina Faso). Rev Neurol (Paris) 2002, 158: 1186-1190.

24. Millogo $A$, Diagana $M$, Siranyan $S A$, et al. Itinéraire thérapeutique des épileptiques consultant dans le centre hospitalier de Bobo-Dioulasso (Burkina Faso). Epilepsies 2003, 15: 153-156.

25. Millogo A, Siranyan SA. Knowledge of epilepsy and attitudes towards the condition among schoolteachers in Bobo-Dioulasso (Burkina Faso). Epileptic Disord 2004, 6: 21-26.

26. Millogo A, Ratsimbazafy $V$, Nubukpo $P$, et al. Epilepsy and traditional medicine in BoboDioulasso (Burkina Faso). Acta Neurol Scand 2004, 109: 250-254.

27. Carabin H, Millogo A, Praet N, et al. Evaluation du Fardeau Economique de la Cysticercose au Burkina Faso (EFECAB). Seroprevalence to the antigens of Taenia solium cysticercosis among residents of three villages in Burkina Faso: A cross-sectional study. PLoS Negl Trop Dis 2009; 3(11): e555.

28. Ganaba R, Praet N, Carabin H, et al. Factors associated with the prevalence of circulating antigens to porcine cysticercosis in three villages of Burkina Faso. PLoS Negl Trop Dis 2011, 5(1): e927.

29. Nitiema P, Carabin H, Hounton S, et al. Prevalence case-control study of epilepsy in three Burkina Faso villages. Acta Neurol Scand. 2012; 126(4):270-278. 
30. Millogo A, Nitiema $\mathrm{P}$, Carabin $\mathrm{H}$, et al. Prevalence of neurocysticercosis among people with epilepsy in rural areas of Burkina Faso. Epilepsia 2012; 53: 2194-2202.

31. Qualitative data analysis [http://www.sagepub.com/upm-data/43454_10.pdf] site accessed 2007.

32. Arborio S, Dozon JP. Dimension socioculturelle de l'épilepsie (kirikirimasien) en milieu rural bambara (Mali). Bull Soc Pathol Exot 2000; 93: 241-246.

24. Winkler AS, Mayer M, Schnaitmann S, et al. Belief system of epilepsy and attitudes toward people living with epilepsy in a rural communities of Northern Tanzania. Epilepsy Behav 2010, 19: 596-601.

33. Birbeck GL. Seizures in rural Zambia. Epilepsia 2000; 41: 277-281.

34. Preux PM, Tiemagni F, Fodzo L, et al. Antiepileptic therapies in the Mifi Province in Cameroon. Epilepsia, 2000; 41: 432-439.

35. Mushi D, Hunter E, Mtuya C, et al. Social-cultural aspects of epilepsy in Kilimanjaro Region, Tanzania: Knowledge and experience among patients and carers. Epilepsy Behav 2011, 20: 338-343.

36. Birbeck G, Chomba E, Atadzhanov M, et al. The social and economic impact of epilepsy in Zambia: a cross-sectional study. Lancet Neurol 2007; 6: 39-44.

37. Mbuba CK, Newton CR. Packages of care for epilepsy in low- and middle-income countries. PLoS Med 2009, 6(10): e1000162. 


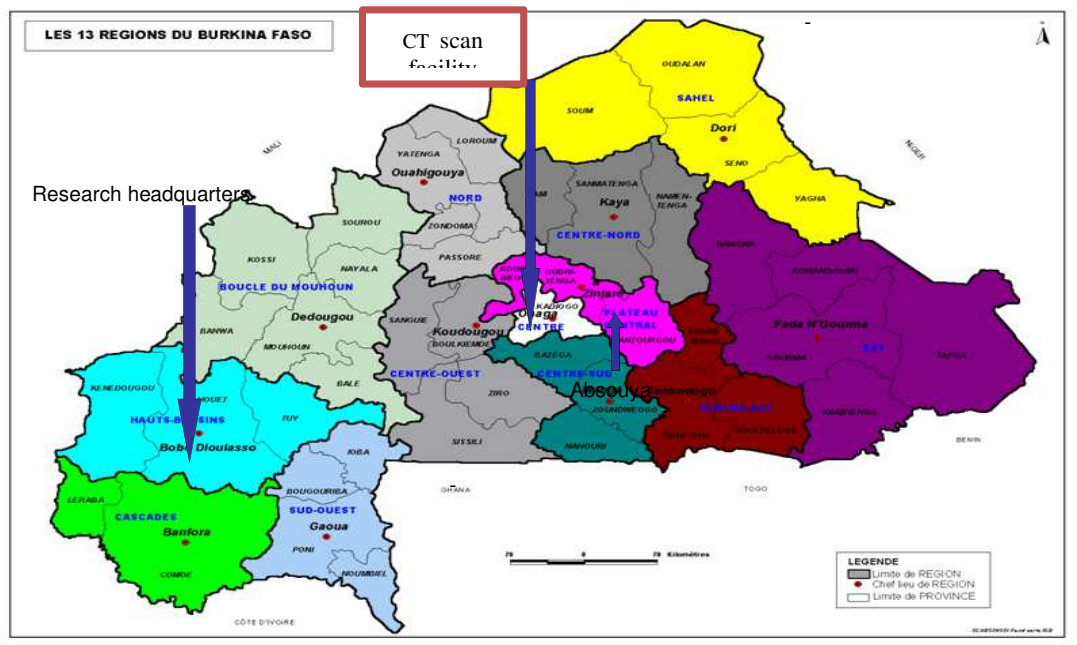

Figure 1: Location of the 3 pilot villages, the research headquarters and of the CT scan facility (Map adapted from http:// www.insd.bf/) 